complication of less than one in a thousand. (Venepuncture is agreed to carry minimal risk.) Investigators should themselves explain projects to parents, and if the risk is more than minimal they should give a written explanation and time for the parents to consider this. Children aged 7 or over should give their own assent to a procedure-in addition to the necessary consent of the parents. If the child is between 7 and 14 his unwillingness to take part in non-therapeutic research should be binding, but his parents could override his unwillingness to take part in therapeutic research. Over 14 the young person's view should be paramount, though parental consent is still legally required until 16 for therapeutic, and until 18 for non-therapeutic, research.

The institute recommends that a paediatrician or child expert should be present when research on children is being discussed. He should probably be a full member of the committee if proposals for research in children are likely to be considered at most meetings, but committees must remain small enough for their members to take real responsibility.

The responsibility of the investigator for the ethics of his research cannot be emphasised too strongly, and a possible drawback of research ethics committees is that they may appear to relieve the investigator of some of this responsibility. ${ }^{6}$ Submitting an application to the committee should mean that the investigator is entirely happy about the proposed research. If he has doubts he should be able to ask guidance of the committee in a different way.
One of the most difficult subjects is informed consent in controlled trials, particularly in the newborn. ${ }^{7}$ A policy such as that of the Institute of Medical Ethics, which is strict in its requirement for informed consent, may impose a double standard since the committees cannot stop new treatment $c$ being tried in an uncontrolled way. ${ }^{8}$ The institute's reply is that the number of times an innovative treatment may be used on children without it being submitted as a formal research project to a research ethics committee should be limited. This debate continues, ${ }^{9}$ but opinion is likely to move increasingly towards full discussion of all facts with patients or their parents.

ROGER J ROBINSON

Professor of Paediatrics,

United Medical and Dental Schools of Guy's and St Thomas's Hospitals, Guy's Hospital,

London SE1 9RT

1 Institute of Medical Ethics. Research ethics committees. Institute of Medical Ethics Bulletin 1986;18(suppl 2):1-19.

Nicholson RH, ed. Medical research in children: ethics, law, and practice. Oxford: Oxford University Press, 1986.

3 Royal College of Physicians of London. Guidelines on the practice of ethics committees in medical research. London: Royal College of Physicians, 1984.

4 Anonymous. Research on healthy volunteers [Editorial]. Lancet 1986;ii:900-1.

5 Anonymous. Guidelines: medical research with children: ethics, law and practice. Insinue of Medical Ethics Bulletin 1986;14(May):8-9.

Medical Ethics Bulletin 1986;14(May):8-9.
Lewis PJ. The drawbacks of research ethics committees. Joumal of Medical Ethics 1982;8:61-4.

6 Lewis PJ. The drawbacks of research ethics committees. Four

Tarnow-Mordi W. Informed consent. Br Med f 1986;293:562

8 Baum M. Do we need informed consent? Lancet 1986;ii:911-2.

9 Glover J. The MRC and informed consent. Br Med f 1986;293:157-8.

\section{Children, bikes, and money}

Adventurous children injure themselves (and may die) in accidents. In some societies they fall out of trees' ${ }^{1}$; in others they may drown. ${ }^{2}$ In Britain and other Western countries the leading cause of accidental injuries and deaths is road traffic accidents; these account for one quarter of all deaths between the ages of 5 and 14. The resurgence of interest in bicycles in recent years has been accompanied, sadly, by an increase in the numbers of children injured or killed on bikes. ${ }^{3}$ Some at least of these deaths and injuries are preventable.

At $\mathrm{p} 1267$ we publish a detailed study by Nixon $e t$ al from Australia of 891 bicycle accidents over 10 years. Boys had far more accidents than girls, and the peak age was 12-14. Most (32) of the 46 deaths were due to head injuries; in 40 (87\%) the cyclist was in collision with a motor vehicle or a train. A similar study in Philadelphia analysed 520 children injured while riding bikes. ${ }^{4}$ Again more $(72 \%)$ were boys. One third were stunt riding or "riding too fast" at the time of the accident. Only three riders were wearing protective helmets. Most of the injuries were minor and none of the children died-but in the United States around 600 children die each year in bicycle accidents.

What, then, about prevention? Firstly, Nixon et al and the American authors are agreed that fewer children would be injured severely or die if all cyclists wore helmets. Next, cyclists-and especially child cyclists, who are inexperienced, impatient, and adventurous-should be separated from other traffic. They should also be given formal training in road safety; police forces which organise cycling proficiency courses not only teach useful skills but also help improve relations between children and the police. Half the children injured in the Philadelphia series had had no instruction at all on safety or road sense.

The design and marketing of bicycles have changed as they have become more popular. Stunt bikes are advertised on television as play machines, and children given these bikes are encouraged to ride them in a spectacular style. A study in Britain of 100 children injured while on BMX bikes found that no fewer than 40 had been attempting stunts, ${ }^{5}$ a finding in line with evidence from the United States. ${ }^{4}$ These bikes seem less than ideal when used simply for transport: at $p 1259$ we report two cases of teenagers who injured their spines in road accidents which concerned no other vehicles.

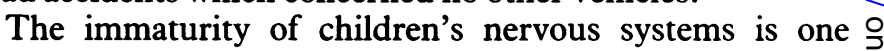
reason for their vulnerability to accidents; and if they are at N risk when using bicycles these risks are even higher when $\rightarrow$ they use motor bikes and "off the road" vehicles. The state- 을 acting as a guardian-forbids children under the statutory ages to drive motor bikes or cars on the highway. Off the road, however, parents may, and do, buy their children vehicles (and for that matter allow them to drink alcohol and 0 play with guns) while unbelievably young.

Parental irresponsibility is one thing; commercial exploitation of that irresponsibility is another. At page 1259 three surgeons from Belfast report serious injuries and one death in children aged 8-15 years riding motorcycles, including both adult bikes and junior scramblers or other vehicles marketed for use "off the road." Some motorcycle clubs organise races for youngsters on bikes of this type.

Experience in the United States has shown that off the road vehicles have become a substantial cause of injuries and 
death in childhood. ${ }^{6}$ This is another preventable epidemic. Both the marketing of these vehicles and their use should, we believe, be restricted. The Belfast surgeons suggest a minimum age of 12 , and that seems a reasonable compromise between paternalistic intervention and laisser faire, but a higher limit would save more lives and limbs.

As with tobacco and alcohol, the public health issue is the disproportion between the commercial investment in selling to children bikes-and stunt bikes, junior scramblers, and all terrain vehicles-and the tiny amount of information given to parents on their safety aspects. Probably most parents are unaware of the high accident rates associated with cycling and the higher rates with these fashionable transport toys. Only those who travel abroad will be aware that in some countries cyclists and playing children are much better separated from traffic than in Britain. ${ }^{7}$ Much more effort should, I believe, be made in Britain to reduce the toll of accidents both among children using bikes simply to get from one place to another and those using them for fun. The prime action required is recognition by community physicians, schoolteachers, policemen, and parents that the child acci- dent rate can be reduced if the community is willing to make some changes. Ideally all child cyclists should have been trained in road safety; and the roads they use should be made as safe as possible.

In Western societies accidents have replaced infections as the prime cause of death in childhood. The morbidity and mortality from infections preventable by immunisation may be the best marker of a state's concern for its children's health-but the accident rate may well be almost as susceptible to determined efforts in prevention.

\section{TONY SMITH}

Deputy editor, $B M \mathcal{F}$

\footnotetext{
1 Barss $P$, Dakulala $P$, Doolan $M$. Falls from trees and tree associated injuries in rural Melanesians. BrMed f 1984;289:1717-20.

2 Pearn J. The management of near drowning. Br Med f 1985;291:1447-52.

3 Anonymous. Motor cycle and bicycle accidents. Br Med $\mathcal{f}$ 1979; i:39-41.

4 Sebsr SM, Alexander D, Ruddy R. Bicycle-related injuries. Am J Dis Child 1987;141:140-4.

5 Illingworth CM. Injuries in children riding BMX bikes. Br Med f 1984;289:956-7.

6 Stevens WS, Rodgers BM, Newman BM. Pediatric trauma associated with all-terrain vehicles. I Pediatr 1986;109:25-9.

7 Avery JG, Avery PJ. Scandinavian and Dutch lessons in childhood road traffic accident prevention. BrMed F 1982;285:621-6.
}

\section{Standards for blood pressure measuring devices}

\section{In 1985 the British Hypertension Society established a working party on blood pressure measurement to make recommendations on the technique of measurement, and the recommendations have now been published. ${ }^{12}$ The working party was also asked to improve the accuracy of measuring devices and examine the feasibility of providing minimal standards for all such devices. The introduction and enforce- ment of such standards are urgently needed because semi- automated devices of unproved accuracy are proliferating to cater for the increasing market for self measurement of blood pressure. Technically complex and extremely expensive semiautomated devices for operating theatres and intensive care areas have also been successfully marketed, often without independent validation. Ambulatory blood pressure measuring systems are increasingly in demand as well and are not only costly but also are often exorbitantly expensive to operate and maintain.}

As a first step the working party set out to determine what standards, if any, existed in other countries and how manufacturers were made to comply with such standards. ${ }^{3}$ None of the European countries approached appears to have effective standards, and those standards that do exist are out of date. ${ }^{46}$ In Britain, Ireland, and most of Europe the validation of automated and semiautomated blood pressure measuring devices depends on independent researchers with an interest in blood pressure measurement. ${ }^{7-9}$ The British Standards Institution is reviewing its standards for mercury and aneroid sphygmomanometers, and recently the biomedical engineering group of the Committee for Medical Research of the European Community approved a project to coordinate research on ambulatory monitoring, which is to include assessing the prognostic value of ambulatory blood pressure recording in patients with hypertension. ${ }^{10}$ This project will inevitably call for an appraisal of devices used for the non-invasive assessment of ambulatory blood pressure. Recently the Australian Standards Committee has drafted stringent proposals to improve standards, ${ }^{112}$ and comprehensive standards for blood pressure measuring equipment have been operating for several years in the United States. ${ }^{13-18}$ With advances in technology, however, even these standards are now outdated, and the Association for the Advancement of Medical Instrumentation has recently revised the standards for mercury and aneroid sphygmomanometers ${ }^{19}$ and is now finalising its recommendations for automated devices. ${ }^{20}$

Having ascertained policy elsewhere, the working party recommends that the existing standards ${ }^{45}$ for mercury and aneroid sphygmomanometers should be revised without delay. It also proposes to draw up comprehensive standards on the accuracy, efficiency, and safety of semiautomated and automated devices and to consider their cost-not only to buy but also to maintain.

But how can standards be enforced? Clearly neither the British Hypertension Society nor any other body can validate all blood pressure measuring devices on the market. The only practical solution is to make manufacturers produce evidence that they have complied with the standards. Though standards may eventually be enforced by legislation, ${ }^{21}$ the British Hypertension Society proposes to ask bodies such as the Department of Health and Social Security, the Scottish Home and Health Department, the British Standards Institute, the Medical Research Council, the Department of Health in Ireland, the British and Irish Heart Foundations, and the British and Irish Cardiac Societies to recommend purchase only of blood pressure measuring equipment that satisfies the standards. A regulatory procedure will be needed to process applications from manufacturers for approval of equipment, and facilities will have to be created to provide at least random assessment and validation of new devices. The British Hypertension Society, perhaps in association with the British Standards Institute, could designate and support one or more laboratories like this in Britain and Ireland.

In the meantime, what recommendations can be made to 